\title{
1.6. STRESS AND FATIGUE'S MONITORING BY MEANS OF AFTERIMAGE AS A METHOD OF DECREASING THE NUMBER OF ACCIDENTS AND WRONG DECISIONS
}

\begin{abstract}
Summary
The aim of presented work is to propose a method of examining and monitoring psychophysical condition of managers and employees who hold responsible positions that require high decisional efficiency. Based on the existing empirical and theoretical knowledge, it is here assumed that lateralization and brain's hemispheres' cooperation are closely related to stress, fatigue and well-being. Aftereffect is presented here as a method of measurement of lateralization and its level. Exemplary experimental procedures of this phenomenon and its interpretation in terms of psychophysical condition are described. Development of method of psychophysical condition's measurement that will include stress, fatigue or personal problems that frequently lead to desperate behaviour at work or elsewhere is highly worthwhile. This development as well as practical use of aftereffect to monitor the psychophysical state will surely contribute to reduction of accidents' at work rate and will increase the probability of taking accurate decisions by managers as well as it will facilitate adoption of life style that promotes good psychophysical condition.
\end{abstract}

Keywords: psychophysical condition, brain's hemispheres cooperation, lateralization, aftereffect, stress, fatigue, accidents rate, decisional errors

\section{Introduction}

As it is said by English, wrong decisions most commonly are not the effect of lack of substantive knowledge but are caused by tension, stress or fatigue. So called human factor is a cause of not only many mistakes made by managers but, what should be also noticed, it is a main source of many of accidents and catastrophes that are taking place in other occupations. Nowadays, condition of employees is measured in form of obligatory periodic health examinations, but do they include psychophysical condition as well? In practice this issue is left either to the employee him(her)self or to his/her immediate supervisor. But from where the concerned person or the supervisor can get the knowledge of current psychophysical state? It is not easy to notice tension or stress in oneself, especially when one is experiencing problems on daily basis and every difficulty is attributed to the external world. Researches show that for example pilots have difficulties in specifying their condition and level of psychological tension (Beaty, 1995) succumbing to illusions what is a common cause of air accidents (Bednarek, 2011). So is there any method which would be accurate and which would allow for frequent examinations that would specify psychological condition and then 
based on them to decide what kind of work or what task should be undertaken in given moment? Wouldn't it be good to have this kind of measuring tool, to monitor on the regular and frequent basis employee's psychophysical state, and not only to check his /her suitability to work on certain post every now and then? The aim is not to impose additional restrictions or formalism that would constitute an additional burden to the employee or the supervisor but the authentic attention and care about his/her condition, the quality and safety of performed work. This kind of knowledge would be certainly important not only for managers, who could learn how to manage themselves in better way but also for people working as pilots, lifeguards, or solders executing important tasks or missions.

As an answer to above stated problem in this paper, it is proposed to apply the aftereffect phenomenon to the diagnosis of the level of brain hemispheres' cooperation that conditions and reflects psychophysical state of the examined individual.

\section{The need of monitoring employee's psychophysical condition based on European Agency's report concerning work related stress}

In recent years the society's awareness that presence of long-term stress has adverse effects for employees' health has risen. Considering that, the European Agency commissioned the report (Cox et al., 2002) which would evaluate the situation at the work market in terms of stress' presence. The report reviews stress' nature, its causes, sizes and problems related to it as well as ways of coping with stress. The report concentrates on work environment and covers stress influence on individual employees as well as on organization as a whole thus providing a "business approach" in battle with discussed threats. It suggests practical approach to battle stress in work and points to number of areas where additional researches are inevitable so the ability of managing this problem could increase. The importance of this issue is huge, especially if it is known for a long time now that long-term exposure to stressors works in immunosuppressive manner and causes atrophy of neurons in central nervous system, thus leading to decrease in physical and intellectual efficiency (Karten and Olariu, 2005).

What are the sizes and importance of work-related stress? Problem of work-related stress concerns millions of European employees in all of the employment sectors. For example in research of European Foundation from 2008 about work conditions in European Union, 28\% of employees reported health problems related to presence of stress in work (it is second most common reported health problem after the spine injuries - 38\%). That is around 41 million of employees in European Union who are affected every year by the problem of stress in work and it corresponds to many millions of lost working days (all of the cases of work-related diseases correspond to around 600 millions of working days lost every year in European Union). It is a major reason for concern and a challenge, not only due to the consideration of individual employees' health but also due to the costs and economic influence on business and social costs for European countries.

What actually work-related stress is? Its problem lies mainly in the shaping and managing of the work organization. Stress in relation to work environment is defined 
as „mutual interaction” between the employee and work environment (employee's exposure to risks related to the work environment). In this model stress can be described as occurring if requirements posed by the work environment exceed the employee's capacity to cope with them (control them).

Recent researches on psychophysical risks at work, that are experienced by employees as stressful, show that they entail huge destructive potential that has negative influence on organization's culture, work environment, career, decisions making, interpersonal relations, work-home relation or workload. This influence is also considered as dangerous and harmful for health. Additional, today's rapid and unprecedented changes in world and organizations transform work world causing among others: increasing number of older employees, teleworking, new information and communication technologies, outsourcing, contract work, globalization and therefore changes in employment models, need of employee's flexibility both in terms of hours and functions of his/her skills, increase in percentage of population working in services sector, as well as work in teams. The sole experience of changes can cause stress, especially in situation when at the same time individuals experience lack of control and involvement as well as uncertainty.

How to prevent stress occurring at work and what are the researches priorities? The report emphasizes the need of existing knowledge's "translation" into practical solutions to problem of stress at work. In order to achieve that usage of cycle of threats' elimination/control as a frame in problem solving is proposed. Cycle of control is a "systematic process by means of which threats are defined, level of risk is analysed and countermeasures are taken as well as employees are protected". This approach is problem solving orientated and is successfully used as a strategy of battling physical threats at work. It is described in European Union's current legislations and constitutes a useful strategy for estimation of all of the psychosocial threats at work. Results of interventions using this approach in order to eliminate stress are very promising though appearing limitations of those results. Success can be defined in categories of profit both for employee as well as for the organization. However, lot of respondents pointed out that their interventions to eliminate stress - which were therefore less efficient did not used full approach of this type on the organizational level but were only targeted at individuals or tried to implement solutions which were invented on the spur of the moment without proper diagnosis of the problem. The evaluation of using only psychological counselling come out as not the best one since counselling helped those employees who already suffered because of stress, therefore it was help offered post factum and in general it referred only to individuals.

The main areas qualified to future researches are coping with stress and stress' evaluation. Efforts should be directed towards interventions which aim to eliminate stress on organizational level, mainly because in the past too narrow approach was used too frequently in problem's definition and too strong emphasis was put on "care and treatment" of individual employees. Moreover, more accurate and systematic methods of intervention's evaluation are necessary. Threats' control and evaluation was proposed. There is also visible need for evaluation and monitoring of many aspects of organization and work's managing - frequently collectively referred to as 
"changing work's world". Those new models of work can entail new, not anticipated so far threats both for employees and organization.

Furthermore, in the report the need of stress' at work analysis in context of other, interlinked problems, such as: social inequalities, social diversity, age, gender, disability and ethnic background were underlined. That information is important for obtaining full perspective on need for elimination of work stress. As main conclusions report pointed out following theses: (1) stress at work can be approached in similar ways as other issues of security and health are approached, (2) future researches on stress should concentrate on interventions on the level of organization as a whole, (3) referring to individual employees, it is necessary to obtain further information on employee's ability to cope with stressful situation, as well as effort to develop new methods of stress' diagnosis should be taken.

\section{Issue of fatigue in psychophysical burdening occupations}

Already in classical literature on fatigue, the "elongated reaction time" as well as "hesitation and deterioration of attention" were pointed out as basic symptom of mental fatigue in employees who exercise occupations which cause deterioration in psychophysical condition, such as drivers. In the case of attention, under fatigue its range decreases what can entail even reduced visual field. Employee's fatigue also causes deterioration of visual perception what results among others in elongation of time of return to normal visual performance after blinding by another vehicle's headlights, what constitutes a considerable risk of accidents during driving at night. Other symptoms of driver's fatigue are problems with information processing and short-term memory, decrease in vigilance level as well as in driving performance. Results of Polish researches (Bąk, 2003) indicates four main indicators of drivers' psychophysical effectiveness, which are subjected to deterioration under fatigue, that are: reaction stability, speed and range of perception, attention and time of motor reaction.

Is it possible to define critical working hours? Based on accidents' analysis which took into account the hour of their occurrence it is possible to distinguish time intervals which are characterized by increased risk of accidents' occurrence. For drivers who drive their vehicles at night the most "difficult" hours are those between midnight and 3 a.m. People have limited capacity of working at night, and this limitation is an effect of circadian rhythm occurring in particular systems (circulatory system, nervous system, respiratory system). For individuals sleeping at night and working during the day ability to work is defined by so-called Lehmann's daily work capacity curve. During the first hour after awakening the capacity to work increases, achieving level above the daily average which persists with only small decrease in early afternoon hours. While for people working at night, efficiency in both physical and mental work is deteriorated and achieves the lowest level between 2:00 and 3:00 a.m. After around five hours from taking up the morning activity (in standard daily rhythm), that is between 12:00 and 2:00 p.m., slight decrease in activity incorrectly linked with need for having meal is observed. It is a time of raised risk of making mistake or accident is occurring resulting from driver's effectiveness deterioration, transitional drowsiness or 
occurrence of micro nap. The critical hours during the ride are also the initial two hours when rested driver tends to overrate his/her abilities. Moreover, on the beginning of the route driver's attention can be distracted by, for example, rout planning or time of the journey. In addition, the last two hours are critical when tired driver while approaching the destination tries to reach it as fast as it is possible.

Presented here analysis results in fact that diagnosis of psychophysical condition is very important and might help in identification of psychophysical overload periods. The question of developing method which would enable reliable and easy way of diagnosing employee's psychophysical efficiency state arises. Below proposal of fatigue and stress, diagnosing method with use of phenomenon of afterimage is presented. Its connection to hemispheres' lateralization enables at the same time stress' evaluation and control by providing stimulus which carries meaning related to the work situation.

\section{Lateralization and brain hemispheres' cooperation as manifestation of psychophysical condition}

In accordance to Broca's notion lateralization, that is functional predominance of one of the body sides (that concerns lower and upper limbs, eyes and ears) over the other is determined by predominance of one of the brain's hemispheres over the other. Left hemisphere controls the functioning of the right side of the body, while right hemisphere controls functioning of left side of the body. Dominance of left hemisphere is manifested in right-handedness, while dominance of right hemisphere is manifested in left-handedness. However, damages in right hemisphere of left-handed people entail symptoms that are both quantitatively and qualitatively (i.e. easiness of recovery of given function) are not closely related with those, that occur in case of damages to left hemisphere of right-handed individuals. That means, that lateralization constitutes a highly complex issue and requires the analysis of functioning of brain as a whole. Dominance of one of the hemispheres can have physiological or pathological character. One person can be left-handed because main nerve impulses are coming from right hemisphere (physiological left-handedness) or because his/her left hemisphere was damaged what led to taking the function over by the right hemisphere (pathological left-handedness). Physiological and pathological right-handedness is explained analogously.

Dominance of one of the hemispheres over the other can be expressed weaker or stronger, therefore one can be identified as clearly and totally right-sided and passing through intermediate stages ambidextrous people can be find - only if hand dominance is considered. Moreover, in one person dominance of different limbs and organs can manifest itself in different ways what leads to distinguishing - apart from homogeneous left- and right- handedness - various forms of crossed lateralization. In order to describe lateralization - most commonly the dominance of hand, eye or leg is examined. Most often it is assumed that physiological left- or right-handed lateralization is determined when we are born what does not mean however that that the learning process, upbringing or various psychophysical states do not influence it. 
Lot of studies showed that different psychophysical disorders, including psychical diseases are linked with lateralization and especially with the cooperation of brain's hemispheres. That concerns also stress, fatigue and well-being that is, generally speaking, psychophysical condition. In other words, if we want to state what is the condition of the employee in order to take care of it, if we want to capture moments in which we should not take important decisions or if we want to decrease the number of accidents at work, development of the tool that would enable us to identify present psychophysical state should be taken on. We should have the diagnostic tool that enables us to identify the state that we are in especially, as it was mentioned, its evaluation based on well-being made but the one who is concerned, is unreliable.

\section{Visual aftereffect as the indicator of employees' lateralization and psychophysical condition}

If lateralization and cooperation of brain hemispheres is so important for evaluation of psychophysical condition, the question of how it can be measured should be posed. Is it possible to measure it during the work time or shortly before starting work, so the evaluation of employee's condition could be made relatively quickly and accurate with possibility of repeating of the examination if necessary? There is a certain rhythm of operating in the workplace and employees must efficiently fulfil their responsibilities what means that there is no much time that could be devoted to diagnostics in type of laboratory examinations.

Phenomenon that meets those requirements is visual aftereffect. It can serve as an indicator of lateralization, and more importantly, it enables specifying level of brain's hemispheres cooperation what allows to evaluate mental condition of employee. It has been relatively long time ago postulated to use this phenomenon in examining of eyes' lateralization (Zazzo, 1974, p. 29), but there were no special reasons to develop this proposal, especially if sufficiently extensive knowledge on importance of functional hemispheres' asymmetry wasn't available. Nowadays we have more detailed knowledge on brain's functioning and modern examination methods, i.e. PET or diffusion tensor imaging technique - DTI (Gazzaniga, 2011). Those methods seem to be so attractive that other proposals remain on the sidelines. Moreover, what is important to presented here considerations, so far visual aftereffects haven't been explained in satisfactory way, thought they still are the subject of many researches and theoretical interpretations, what was presented in several works Anstis, Verstraten and Mather (1998), Harciarek 2014), Anstis (2014). Regardless from its interpretation, this phenomenon enables specifying eyes' lateralization by measurement of duration time of the aftereffect reaction for left and right eye. Whereas the difference in duration times of this phenomenon between each eye is an indicator of the level of side predominance of one or the other eye. The bigger is the difference, the higher is the level of lateralization, that is the level of predominance of one eye over the other. Leftsided lateralization (predominance of the left eye) is interpreted as the dominance of right hemisphere, and right-sided lateralization (predominance of right eye) as dominance of the left hemisphere. 
In examining the aftereffect phenomenon moving stimulus can be used, i.e. disc with printed Archimedes' spiral with the diameter of $35 \mathrm{~cm}$ that is turning with speed of 33 rotations per minute on which examined person is looking for 60 seconds from a distance of $80 \mathrm{~cm}$. After the turning spiral is stopped, the examined person still can see the illusory motion which lasts for some time. Examination of lateralization of the eye based on the aftereffect phenomenon can be conducted also with use of static stimulus, i.e. red square which each side has $3,5 \mathrm{~cm}$ and which is place on white background. In this case the gaze should be fixed for one minute on this square and after that it should be covered with white paper board on which examined person should observe aftereffect in form of fair, lighting square. Duration time of this phenomenon induced either by rotating spiral or by motionless square should be defined for each person separately. Comparison among those duration times constitutes the basis of identifying the level of lateralization. For better reliability of the measurement, it is advisable to repeat the examination, especially since it does not take a long time (single individual examination takes up to 5 minutes).

Based on acquired duration times of aftereffect phenomenon the evaluation of employee's psychophysical condition can be made. If the times of aftereffects in left and right eye are equal, the level of lateralization is low what suggests worse psychophysical condition of the examined person. Also too long duration time of aftereffect reaction or a long time of latency (time period between the cessation of the gaze's fixation and the appearance of the aftereffect) should be interpreted as not good psychophysical state. In order to specify in reliable and accurate way the psychophysical condition of employee standardization examination should be conducted and the measurement of reliability and accuracy of this method should be made.

It is worth noting that objectification of above described examination method is possible if in order to specify duration time of aftereffect also EEG will be used. But this is a future version which surely can take place when this method will prove to be useful, especially in helping in management and in increasing of the level of work efficiency in many occupations that require high psychophysical performance.

Method proposed here, in which aftereffect is an indicator of psychophysical condition, can be practically used in managers' periodic examinations or in situation when he or she has to take an important decision or perform difficult task. In case of psychological state's monitoring by use of this method and in case of stating high inner tension it is possible to apply therapeutic or relaxing actions to reset the optimal level of manager's psychophysical condition.

\section{Conclusion}

Taking into account the human factor accidents and managers' wrong decisions, measuring and monitoring of psychophysical condition is highly desirable. The method proposed above enables not only to evaluate of employee's psychophysical efficiency in relatively short time, but also can be repeatedly used also in the same person without concern that the previous examinations will influence the next one or will prevent them, what often happens in case of psychological examinations. In 
contrary, next examinations due to the experience will be more accurate and correct. Method of diagnosis of psychophysical condition with use of aftereffect that is proposed in this paper should be subjected to standardization as soon as possible, incorporate to practice of managing and include in already existing techniques that help to fight stress and to understand it in better way (Heszen 2013, Grzywacz 2012). Using of this method to monitor the psychophysical condition we can anticipate efficiently and quickly forthcoming state of managers' overload and thereby protect examined person from intense stress, which may occur as culmination of tensions. By this, we will surely contribute to decrease in number of accidents caused by so called human factor.

\section{References}

1. Anstis, S. (2014): Pattern specificity of contrast adaptation, „i-Perception”, Vol. 5, pp.73-74.

2. Anstis, S., Verstraten, F.A.J., Mather, G. (1998): The motion aftereffect, Trends in Cognitive Sciences, Vol. 2, No. 3, pp. 111-117.

3. Bąk, J. (2011): Zmęczenie kierowcy: przyczyny, skutki, zapobieganie, "Bezpieczeństwo Ruchu Drogowego", Vol. 1, pp. 4-7.

4. Beaty, B (1995): The Naked Pilot, Crowood Lane, Ramsbury, Marlborough, Wiltshire

5. Bednarek, H. (2011): Czy piloci ulegają złudzeniom percepcyjnym?, Gdańskie Wydawnictwo Psychologiczne, Gdańsk.

6. Cox, T., Griffiths, A., Rial-Gonzalez, E. (2002): Health Impact of Psychosocial Hazards at Work.

7. Gazzaniga, M. S. (2011): Who's in charge? Free will and the science of the brain, New York: Ecco.

8. Harciarek, M. (2015): Powidok jako nośnik znaczenia percypowanego bodźca, (to appear)

9. Harciarek, M. (2014): Wzrokowy układ poznawczy jako spektrometr, Humanistyka $i$ Przyrodoznawstwo, Nr 20, p. 161-176.

10. Heszen, I. (2013): Psychologia stresu, Wydawnictwo Naukowe PWN, Warszawa.

11. Grzywacz, R. (2012): Problematyka stresu w środowisku studenckim na podstawie badań, in „Medycyna Rodzinna”, p. 36-43.

12. Karten, Y.J., Olariu, A. (2005): Stress in early life inhibits neurogenesis in adulthood, Trends Neurosci; 28:(4), p. 171-2. DOI: 10.1016/j.tins.2005.01.009

13. Zazzo, R. (1974): Metody psychologicznego badania dziecka, PZWL, Warszawa 